\title{
LA DOCTRINA SOCIAL DE LA IGLESIA CATÓLICA Y LA GUERRA DE MONEDAS \\ Roberto Zocco*
}

RESUMEN: En este texto se aborda el tema de la moneda como instrumento de poder y dominación desde el punto de vista de la doctrina social de la Iglesia católica. Aunque no podamos encontrar en ella una enseñanza explícita sobre la moneda como instrumento de dominación, es posible deducir algunas pautas éticas sobre el uso de la moneda.

\section{yod}

\section{CATHOLIC SOCIAL TEACHING AND CURRENCIES' WAR}

ABSTRACT: In this text I address the issue of the currency as an instrument of power and domination from the point of view of the Catholic social teaching. Although we cannot find in it an explicit teaching on the currency as an instrument of domination, it is possible to deduce from the Catholic social teaching some ethical guidelines on the use of currency.

PALABRAS CLAVE: economía, finanzas, moneda.

KEY WORDS: currency, economy, finance.

RECEPCIÓN: 15 de febrero de 2018.

APROBACIÓN: 7 de septiembre de 2018.

DOI: $10.5347 / 01856383.0129 .000294411$

* Departamento Académico de Estudios Generales, ITAM. 
Se prohíbe su reproducción total o parcial por cualquier medio, incluido electrónico, sin permiso previo y por escrito de los editores. 


\section{LA DOCTRINA SOCIAL \\ DE LA IGLESIA \\ CATÓLICA Y LA \\ GUERRA DE MONEDAS}

\section{Premisas}

$\mathrm{E}_{\text {stas observaciones se basan princi- }}$ palmente en un discurso que el actual cardenal secretario del Estado Vaticano Pietro Parolin dio en la presentación de la revista geopolítica italiana Limes en Roma el 31 de marzo de 2015. ${ }^{1}$ Ese número de Limes estaba enteramente dedicado a la guerra de divisas.

El discurso del cardenal Parolin me parece ser la reflexión más completa que las autoridades vaticanas han hecho hasta ahora sobre la relación entre finanzas y política y el poder de la moneda.

Las orientaciones concretas que la doctrina social católica indica se desarrollan en relación con las circunstancias históricas. Por lo tanto, aquí seguiré los acontecimientos históricos que nos han llevado a la situación económica actual y expondré el juicio de la Iglesia católica sobre ellos.

Siguiendo el análisis histórico realizado por el Cardenal Parolin, mi presentación constará de tres partes:

1. Antes y después de las dos guerras mundiales

2. Desde 1945 hasta finales de la década de 1980

3. El mundo de hoy

${ }^{1}$ Cfr. Pietro Parolin, "Per una economia della dignità", Osservatore Romano, $1^{\circ}$ de abril de 2015, en $<$ http://www.osservatoreromano.va/it/news/una-economia-della-dignita.html $>$, consultado el 15 de diciembre de 2017. 
ROBERTO ZOCCO

\section{Antes y después de las dos guerras mundiales}

\section{Intervenciones gubernamentales en economía}

El primer periodo que quiero exponer va desde el comienzo del siglo XX hasta el final de la Segunda Guerra Mundial.

Según el cardenal Parolin, el siglo XX, especialmente después de la Primera Guerra Mundial, se caracterizó de manera uniforme por las intervenciones del gobierno en la actividad económica nacional mediante verdaderos actos de imperio (en el sentido de ejercicio de la más alta autoridad) que determinaban el monto de la moneda circulante y su valor en relación con los bienes, los servicios intercambiados y otras monedas extranjeras. Estos actos de autoridad se dirigían esencialmente a la economía interna y tenían como finalidad garantizar el funcionamiento equilibrado de la economía nacional.

Sin embargo, dado que el desarrollo tecnológico tendió, desde la segunda mitad del siglo XIX, a integrar el mundo en un solo espacio económico, las medidas monetarias nacionales no podían evitar tener un impacto en otros países con los que se mantenían relaciones económicas.

En consecuencia, el intento de limitar los efectos de la expansión y contracción de los ciclos económicos nacionales originó a menudo una competencia económica desleal, que posteriormente provocó un estado de "guerra de divisas". Así, la relación entre moneda e imperio, que antes se entendía como el ejercicio de la más alta autoridad nacional (el imperio de los romanos), se transformó en una hegemonía supranacional. Más tarde, la competencia "salvaje" entre las divisas y los reglamentos financieros nacionales se convirtió en una verdadera guerra sin armas, lo que sentó las bases para una eventual guerra armada real.

El cardenal Parolin está de acuerdo con los analistas que describen con realismo extremo el valor de una moneda de la siguiente manera: "El valor intrínseco de una moneda es la autoridad política y militar de quienes la acuñan, así como su percepción imperial”. Debido a esto, muchos analistas señalaron que las turbulencias económicas y financieras después de la Primera Guerra Mundial fueron la causa de la segunda. 
Conferencias de Bretton Woods y San Francisco (1944-45)

Por esta razón, al final de la Segunda Guerra Mundial la política internacional tuvo la firme intención de asegurar una paz duradera mediante la articulación de un sistema regulador que tenía que ocuparse de todos los conflictos entre naciones, incluidos los económicos, y al que debían presentarse incluso las reclamaciones en contra de actitudes imperiales o hegemónicas de parte de un Estado.

Las conferencias de Dumbarton Oaks (1944) y San Francisco (1945), que dieron origen a las Naciones Unidas, fueron la culminación de un proceso que incluyó la creación del Fondo Monetario Internacional y del Banco Internacional para la reconstrucción y el desarrollo del ahora Grupo del Banco Mundial (World Bank Group), que tenía que integrar la creación de la Organización Internacional del Comercio en la Conferencia de La Habana (1947-1948), la cual, sin embargo, no tuvo éxito.

Con estas nuevas instituciones, se suponía que las finanzas internacionales y el comercio mundial funcionarían armoniosamente con la coordinación internacional de todos los asuntos políticos, comenzando con la renuncia definitiva a la guerra.

La paz duradera prevista por el proyecto de 1944-1945 tenía que basarse en cuatro grandes pilares:

1. La supremacía del derecho internacional.

2. Un sistema supranacional de solución pacífica de los conflictos.

3. La armonización pacífica y sincera de las finanzas y de los intercambios comerciales.

4. Los intercambios culturales entre los pueblos, garantizados por la UNESCO, cuya creación se había previsto para la Conferencia de Londres de 1944 y que finalmente se concretó en París en 1946.

Todo esto, además, tenía que fundamentarse en una actitud ética o moral de los Estados y de los actores políticos; de lo contrario, el edificio pensado para garantizar la paz siempre correría el riesgo de colapsar. 
ROBERTO ZOCCO

\section{La enseñanza de la Iglesia católica antes \\ y después de las guerras mundiales}

El cardenal Parolin señaló que, en general, como la Iglesia católica condena el nacionalismo extremo y las guerras, debe concluirse que condena también implícitamente las "guerras financieras", en las que la manipulación de la moneda nacional se convierte en un instrumento por el cual los Estados imponen su supremacía u ofrecen beneficios a sus ciudadanos en detrimento de los de otros Estados. Por lo tanto, la opinión de la doctrina social de la Iglesia sobre las cuestiones financieras está ya presente implícitamente en el juicio moral sobre la economía y su capacidad para respetar la dignidad humana y apoyar a los más pobres.

Después de eso, el cardenal Parolin recordó que en la perspectiva del proyecto de creación de las Naciones Unidas, incluidas las instituciones de Bretton Woods, sería útil volver a leer la carta del Papa Benedicto XV del $1^{\circ}$ de agosto de 1917, dirigida a los líderes de los pueblos beligerantes. Ahí están esbozados, proféticamente, los cuatro pilares ya mencionados para lograr una paz justa y duradera. ${ }^{2}$

En la misma carta se recordaba a las naciones en guerra que el conflicto bélico se había desatado por razones económicas egoístas de los Estados.

El cardenal Parolin recordó también que la petición de Benedicto XV era, sobre todo, un fuerte llamado ético a la responsabilidad de los

2 "E primieramente, il punto fondamentale deve essere che sottentri alla forza materiale delle armi la forza morale del diritto. Quindi un giusto accordo di tutti nella diminuzione simultanea e reciproca degli armamenti secondo norme e garanzie da stabilire, nella misura necessaria e sufficiente al mantenimento dell'ordine pubblico nei singoli Stati; e, in sostituzione delle armi, l'istituto dell'arbitrato con la sua alta funzione pacificatrice, secondo e norme da concertare e la sanzione da convenire contro lo Stato che ricusasse o di sottoporre le questioni internazionali all'arbitro o di accettarne la decisione. Stabilito così l'impero del diritto, si tolga ogni ostacolo alle vie di comunicazione dei popoli con la vera libertà e comunanza dei mari: il che, mentre eliminerebbe molteplici cause di conflitto, aprirebbe a tutti nuove fonti di prosperità e di progresso. Quanto ai danni e spese di guerra, non scorgiamo altro scampo che nella norma generale di una intera e reciproca condonazione, giustificata del resto dai benefici immensi del disarmo; tanto più che non si comprenderebbe la continuazione di tanta carneficina unicamente per ragioni di ordine economico. Che se in qualche caso vi si oppongano ragioni particolari, queste si ponderino con giustizia ed equità." Papa Benedicto XV, Lettera del Santo Padre Benedetto XV ai capi dei popoli belligeranti, $1^{\circ}$ de agosto de 1917, en $<\mathrm{https}$ :/w2.vatican.va/ content/benedict-xv/it/letters/1917/documents/hf_ben-Xv_let_19170801_popoli-belligeranti. html>, consultada el 15 de diciembre de 2017. 
líderes políticos, cuyo primer y absoluto deber es proporcionar: "la paz y la alegría de innumerables familias, la [...] felicidad misma de los pueblos, que ustedes tienen el deber absoluto de asegurar". 3

La visión de la comunidad internacional como "familia de naciones" está implícita en esta súplica de Benedicto XV. Sin embargo, fue el papa Pío XII, en su discurso del 25 de febrero de 1946 ante el cuerpo diplomático, el que usó por primera vez el término "familia de las naciones", dando forma así a un concepto que sería después retomado por sus sucesores, especialmente por el papa Juan Pablo II. ${ }^{4}$

En esta concepción de la comunidad internacional como "familia" no hay lugar para ningún tipo de guerra, no solo para la guerra armada, sino tampoco para las guerras financieras, comerciales o culturales.

San Juan Pablo II, el 5 de octubre de 1995, ante la Asamblea General de las Naciones Unidas, habló nuevamente de la comunidad internacional como "familia de pueblos y naciones" y se centró en la descripción de las relaciones familiares, cuya finalidad va mucho más allá de la creación de equilibrios políticos y jurídicos. Es útil aquí citar directamente sus palabras:

Es necesario que la Organización de las Naciones Unidas se eleve cada vez más de la fría condición de institución de tipo administrativo a la de

${ }^{3}$ Loc. cit. (traducción del autor).

${ }^{4}$ El 4 de octubre de 1965, el papa Paulo VI se dirigió a las Naciones Unidas al hablar de la "gran familia de los pueblos" (véase Paulo VI, Visita del Sumo Pontífice Paulo VI a la Organización de las Naciones Unidas. Discurso a los representantes de los Estados, 4 de octubre de 1965, en <https://w2.vatican.va/content/paul-vi/es/speeches/1965/documents/hf_pvi_spe_19651004_united-nations.html>, consultada el 15 de diciembre de 2017), y el 5 de octubre de 1995, san Juan Pablo II volvió a hablar de la comunidad internacional como "familia de los pueblos y de las naciones" y se centró en la descripción de las relaciones familiares, que van mucho más allá de los equilibrios políticos y jurídicos (Juan Pablo II, Discurso de su Santidad el Papa Juan Pablo II a la quincuagésima Asamblea General de las Naciones Unidas, 5 de octubre de 1995, en <http://w2.vatican.va/content/john-paul-ii/es/speeches/1995/october/ documents/hf_jp-ii_spe_05101995_address-to-uno.html>, consultada el 15 de diciembre de 2017). Por último, el papa Benedicto XVI, en su discurso ante la Asamblea General de las Naciones Unidas el 18 de abril de 2008, retomó e insistió en el concepto de "familia de las naciones" (Benedicto XVI, Viaje apostólico a los Estados Unidos de América y visita a la sede de la Organización de la Naciones Unidas. Encuentro con los miembros de la Asamblea General de las Naciones Unidas. Discurso de su Santidad Benedicto XVI, 18 de abril de 2008, en $<$ https://w2.vatican.va/content/benedict-xvi/es/speeches/2008/april/documents/hf_ben-xvi_ spe_20080418_un-visit.html>, consultada el 15 de diciembre de 2017). 
centro moral, en el que todas las naciones del mundo se sientan como en su casa, desarrollando la conciencia común de ser, por así decir, una "familia de naciones". El concepto de "familia" evoca inmediatamente algo que va más allá de las simples relaciones funcionales o de la mera convergencia de intereses. La familia es, por su naturaleza, una comunidad fundada en la confianza recíproca, en el apoyo mutuo y en el respeto sincero. En una auténtica familia no existe el dominio de los fuertes; al contrario, los miembros más débiles son, precisamente por su debilidad, doblemente acogidos y ayudados. ${ }^{5}$

\section{Desde 1945 hasta finales de la década de 1980}

\section{El mundo desde 1945}

El escenario internacional, por lo menos desde 1945 hasta el término de la década de 1970, estuvo influido en gran parte por las condiciones que determinaron el proyecto de Bretton Woods. Dentro de ciertos límites, esta época significó un verdadero desarme financiero, aunque hay que notar también que los países en desarrollo y la sociedad civil criticaron el sistema de Bretton Woods por su desequilibrio a favor de los países más desarrollados, debido a la insuficiente asistencia directa hacia los países en desarrollo y a la ayuda financiera en forma de crédito por pagar, que a menudo se convirtió en usura.

Según el cardenal Parolin, la economía global se estructuró, en términos generales, en una serie de "cajas cerradas", de "Estados o economías nacionales" que tenían relaciones económicas entre ellas. Los mercados financieros, es decir, el crédito, la creación de dinero, el comercio, etc., estaban relativamente controlados y gobernados por los Estados. Los flujos financieros especulativos internacionales eran algo secundario y los países estaban conectados por medio del intercambio de bienes y sus pagos.

\footnotetext{
${ }^{5}$ Juan Pablo II, op. cit.
} 
En este contexto, las finanzas globales eran más accesorias a las relaciones comerciales internacionales y a menudo estaban mediadas o controladas por los Estados mediante el monopolio o la supervisión de las transacciones en divisas y el financiamiento de las exportaciones e importaciones.

Junto con la financiación del comercio, otro capítulo de las finanzas internacionales consistía en préstamos preferenciales otorgados por gobiernos u organismos multilaterales que iban dirigidos al desarrollo estructural de los países más pobres (esta es la finalidad del Banco Mundial) o a destinar créditos para enfrentar dificultades temporales de la balanza de pagos (en última instancia, con un objetivo vinculado al comercio internacional).

\section{La enseñanza social católica}

Según el cardenal Parolin, en este contexto la encíclica Populorum Progressio de Paulo VI es particularmente significativa. En los primeros párrafos del segundo capítulo, titulado "El desarrollo solidario de la humanidad", ${ }^{6}$ el papa dedica un amplio espacio al desarrollo de un sistema justo de comercio internacional. ${ }^{7}$

El tema de las finanzas, por otro lado, no es tratado en lo general, sino que es objeto de una propuesta específica: la creación de un "Fondo Mundial" para países desfavorecidos, impulsado por una parte del gasto militar. ${ }^{8}$

El cardenal Parolin señaló que, por lo tanto, esta sugerencia financiera solo buscaba contribuir a colmar las lagunas del proyecto del Banco Mundial. En resumen, en el mundo de las "cajas cerradas" de Bretton Woods, era el momento de abrir "cajas" para el comercio justo y la cooperación internacional.

${ }^{6}$ Paulo VI, Populorum Progressio, 26 de marzo de 1967, nn. 43-65, en <http://w2.vatican. $\mathrm{va} /$ content/paul-vi/es/encyclicals/documents/hf_p-vi_enc_26031967_populorum.html $>$, consultada el 15 de diciembre de 2017.

${ }^{7} \mathrm{Ibid}$. En particular nn. 43-44 sobre la "Fraternidad de los pueblos" y nn. 56-65 sobre "La justicia social en las relaciones comerciales".

${ }^{8}$ Ibid. En particular nn. 51-55. 
Paulo VI no se limitó a las exhortaciones expuestas en la encíclica Populorum Progressio, sino que instó a la diplomacia multilateral de la Santa Sede a comprometerse firmemente, dentro de los límites de sus posibilidades, a la cooperación económica multilateral, siguiendo las líneas trazadas por el magisterio pontificio. Así, al inicio de su pontificado, en 1964, una de las actividades internacionales más importantes de la Santa Sede, como sujeto soberano del derecho internacional, fue la participación activa en la creación de la Conferencia de las Naciones Unidas sobre Comercio y Desarrollo (UNCTAD), ${ }^{9}$ una agencia de la que el Vaticano es uno de los fundadores y de la cual sigue siendo miembro. De hecho, la UNCTAD pretendía ser el pilar faltante en la construcción de las conferencias de Bretton Woods y San Francisco, ya que la Organización Internacional del Comercio, creada en la Conferencia de La Habana en 1946, no sobrevivió porque el Congreso de Estados Unidos no ratificó su participación.

Durante el pontificado de Paulo VI, en 1967, la Santa Sede participó también en la creación de la Organización de las Naciones Unidas para el Desarrollo Industrial (UNIDO). ${ }^{10}$

\section{El mundo hoy}

¿Una nueva situación en las finanzas?

De acuerdo con el cardenal Parolin, desde el final de la Guerra Fría la economía de mercado ha sido aceptada de forma más o menos generalizada o, por lo menos, tiene un papel importante en las relaciones económicas entre los Estados.

Al mismo tiempo, gran parte de la actividad financiera ha sido capaz de "deshacerse" de la "caja" impuesta por los gobiernos y de convertirse en un elemento verdaderamente autónomo, que ahora es norma de sí mismo.

${ }^{9}$ United Nations Conference on Trade and Development, en $<$ http://unctad.org/en/Pages/ Home.aspx>, consultada el 15 de diciembre de 2017.

${ }^{10}$ United Nations Industrial Development Organization, en $<$ https://www.unido.org/>, consultada el 15 de diciembre de 2017. 
De hecho, poco después del comienzo del pontificado de san Juan Pablo II, algunos economistas comenzaron a referirse a esa época como "la era de la euforia financiera", que duró desde mediados de la década de 1960 hasta 2007-2008. Esta época se caracterizó, desde el punto de vista legal y político, por una importante desregulación de las finanzas $\mathrm{y}$, en consecuencia, por una asunción cada vez mayor del poder de los mercados financieros sobre los Estados (de hecho, una verdadera toma de control). Las finanzas terminaron asumiendo la suprema coordinación de las actividades económicas a través de las fronteras.

Esto significó la desaparición del mundo de Bretton Woods, que había durado unos treinta años y dentro del cual se colocaron las enseñanzas de la Populorum Progressio y con ello el fin de la paz financiera "o más bien el fin de la tregua" que este sistema había producido.

Por lo tanto, vino a faltar uno de los cuatro pilares de la paz mundial: "la armonización pacífica y sincera de las finanzas y de los intercambios comerciales".

Curiosamente, al mismo tiempo parecía fortalecerse el cuidado del comercio mediante la creación de la Organización Mundial del Comercio (OMC). Sin embargo, según el cardenal Parolin, esta integración no correspondía totalmente a la idea de integración comercial presente en las enseñanzas de Paulo VI, sino más bien a un acuerdo de paz mercantil o una serie de intereses nacionales y económicos, entre otros, de las grandes corporaciones multinacionales que ya se habían expandido a mercados extranjeros y que exigían más libertad de movimiento. Esta libertad se requería especialmente en términos de competencia y de bajos impuestos de aduana para integrar su producción, aprovechando los menores costos de ciertos países.

La OMC resultó mucho menos funcional para la idea de integración comercial presentada en las enseñanzas de Paulo VI, cuando la arquitectura financiera se derrumbó y las finanzas ya "libres" habían tomado el control de la economía.

El cardenal Parolin reconoce también que la cuarta Conferencia Ministerial de la Organización Mundial del Comercio (Doha, diciembre de 2001) ayudó parcialmente a los países pobres a integrarse a las 
normas de la OMC y a dejar claro que el comercio internacional debía ser un instrumento para el desarrollo y la paz.

En este punto, el cardenal Parolin plantea una nueva cuestión relacionada con la economía internacional y el servicio de la paz: ¿cómo y cuánto pueden las finanzas internacionales "privatizadas, globalizadas e incluso independientes de la producción y el comercio de bienes y servicios" servir a la paz? Para responder a esta pregunta — señaló-, tenemos que retroceder en el tiempo.

Desde la Antigüedad los soberanos han grabado su efigie en las monedas, estableciendo así un estrecho vínculo entre la política y los medios convencionales y simbólicos del intercambio. Mucho antes de la intervención activa del Estado en la economía, la moneda simbolizaba la presencia de la política en los intercambios económicos, principalmente con el fin de garantizar la justicia.

La novedad que se desarrolló más tarde, desde los siglos XIV y XV, consistió en asociar cada vez más ampliamente la moneda como divisa con la política interior y exterior de los Estados nacionales emergentes y con la guerra.

El cardenal Parolin señaló que los inicios de la actividad bancaria y de los instrumentos de crédito comercial en el Renacimiento (primero en Italia y después en los Países Bajos) indican que el crédito se dirigía generalmente a aquellos que tenían el poder político o la capacidad para emprender grandes empresas económicas: a los soberanos y a las grandes compañías de navegación. En fin, se otorgaba el crédito solo a quienes parecían capaces de obtener grandes ganancias. Entre ellos, podemos encontrar a los políticos, porque tienen los medios para devolver los préstamos y pagar los intereses con los pillajes de las guerras o con los impuestos de sus súbditos, y a los marineros y conquistadores, porque obtienen ganancias del comercio de especias, frutas y minerales traídos del extranjero.

El cardenal Parolin plantea entonces la siguiente pregunta: en el escenario mundial de la segunda década del siglo XXI, ¿son las finanzas nuevamente un arma en manos de la hegemonía nacional? Si así fuera — dijo- nos encontraríamos en la misma situación que caracterizó a la humanidad de la paz de Westfalia a la Segunda Guerra Mundial. 
De hecho, el mundo de hoy parece haber vuelto a esa matriz social porque, después de la era del relativo predominio del sistema de Bretton Woods / San Francisco, el acceso al crédito parece reservado de nuevo y sobre todo a los poderosos: a los Estados con mayor capacidad industrial, militar y financiera; a las empresas que desarrollan los productos tecnológicamente más avanzados y rentables, o a quienes pretenden manejar los riesgos del mismo crédito. Es decir, las empresas utilizarían el crédito para imponer su hegemonía en el mercado y los Estados en la comunidad internacional.

En opinión de nuestro autor, no solo el modelo de finales de la Edad Media y del Renacimiento se repite y se amplía, perpetuando el vínculo entre la moneda y el poder, sino que se une a otros dos fenómenos surgidos en la era moderna y contemporánea.

El primero es el intento de dar una seguridad jurídica sólida a los medios de pago con el curso legal de la moneda, lo que refuerza así su papel como símbolo y presencia del poder político. El segundo, que aparece sobre todo en el siglo XX, es la intervención del Estado en la economía para fijar los valores de los medios de intercambio y el intento de controlar la masa de dinero circulante. El mismo fenómeno del crecimiento exponencial del crédito entre finales del siglo pasado y principios del presente, que provocó la crisis de 2008, no es más que una consecuencia de la asociación incorrecta del dinero con el poder, que fomentó erróneamente la expansión del crédito.

El cardenal Parolin se pregunta entonces si el crédito es el que gobierna a los gobiernos o si son los gobiernos los que gobiernan el crédito, y le parece que se encuentran en una relación mutua, como en el Renacimiento, cuando había una asociación fáctica entre los dos sujetos: el gobierno y el sector financiero. El primero utiliza el crédito como instrumento de su actividad nacional e internacional y el segundo aprovecha la situación privilegiada que el Estado le garantiza de una forma u otra.

Por lo tanto, el sector financiero no se ha independizado de la política. Más bien, la necesita para mantener y aumentar cada vez más su "libertad de movimiento". Por lo tanto, trata de dominar a la política, 
ROBERTO ZOCCO

sea respondiendo directamente a las necesidades de crédito del Estado, sea a través del cabildeo.

Al mismo tiempo, como en el pasado, la política busca utilizar las divisas y el crédito como armas de supremacía nacional e internacional.

\section{La enseñanza social católica ante la crisis financiera actual}

¿Cuál es posición de la doctrina social de la Iglesia frente a estas nuevas realidades?

\section{Juan Pablo II}

Es interesante ver cómo san Juan Pablo II, ya incluso en 1987, antes de la caída del Muro de Berlín, advirtió sobre los aspectos peligrosos del nuevo escenario que comenzaba a prosperar. Al referirse a los problemas de los países en desarrollo, el papa escribió palabras proféticas sobre la relación entre moneda e imperio en la encíclica Sollicitudo Rei Socialis:

Es necesario denunciar la existencia de unos mecanismos económicos, financieros y sociales, los cuales, aunque manejados por la voluntad de los hombres, funcionan de modo casi automático, haciendo más rígidas las situaciones de riqueza de los unos y de pobreza de los otros. Estos mecanismos, maniobrados por los países más desarrollados de modo directo o indirecto, favorecen a causa de su mismo funcionamiento los intereses de los que los maniobran, aunque terminan por sofocar o condicionar las economías de los países menos desarrollados. Es necesario someter en el futuro estos mecanismos a un análisis atento bajo el aspecto ético-moral. ${ }^{11}$

En la encíclica Sollicitudo Rei Socialis, en el punto número 19, Juan Pablo II también se enfrentó al problema de la deuda externa de los países en desarrollo, tema que se convertiría en el centro del Gran Jubileo del 2000.

${ }^{11}$ Juan Pablo II, Sollicitudo rei socialis, 30 de diciembre de 1987, n. 16, en $<\mathrm{http}$ ://w2.vatican. va/content/john-paul-ii/es/encyclicals/documents/hf_jp-ii_enc_30121987_sollicitudo-rei-socialis. html $>$, consultada el 15 de diciembre de 2017. 


\section{Benedicto XVI}

El moderno abuso del crédito fue abordado por Benedicto XVI en la encíclica Caritas in Veritate:

El desarrollo de los pueblos se degrada cuando la humanidad piensa que puede recrearse utilizando los "prodigios" de la tecnología. Lo mismo ocurre con el desarrollo económico, que se manifiesta ficticio y dañino cuando se apoya en los "prodigios" de las finanzas para sostener un crecimiento antinatural y consumista. Ante esta pretensión prometeica, hemos de fortalecer el aprecio por una libertad no arbitraria, sino verdaderamente humanizada por el reconocimiento del bien que la precede. Para alcanzar este objetivo, es necesario que el hombre entre en sí mismo para descubrir las normas fundamentales de la ley moral natural que Dios ha inscrito en su corazón. ${ }^{12}$

En el mismo texto, Benedicto XVI habla de la actitud ética que debe dar forma a toda la actividad financiera y de la necesidad de crear nuevas formas de finanzas, desde la base, como las cooperativas, las empresas de comunión o los montepíos de la Alta Edad Media. ${ }^{13}$

\section{Francisco}

De acuerdo con sus predecesores, el papa Francisco vuelve a estigmatizar la especulación financiera, abordándola primero desde el punto de vista de la reducción antropológica y asociándola después con las crisis mundiales.

La crisis financiera que atravesamos nos hace olvidar que en su origen hay una profunda crisis antropológica: ¡la negación de la primacía del ser humano! Hemos creado nuevos ídolos. La adoración del antiguo becerro de oro (cf. Ex 32,1-35) ha encontrado una versión nueva y despiadada en el fetichismo del dinero y en la dictadura de la economía sin un rostro $\mathrm{y}$ sin un objetivo verdaderamente humano. La crisis mundial, que afecta

${ }^{12}$ Benedicto XVI, Caritas in Veritate, 29 de junio de 2009, n. 68, en $<$ http://w2.vatican.va/ content/benedict-xvi/es/encyclicals/documents/hf_ben-xvi_enc_20090629_caritas-in-veritate. $\mathrm{html}>$, consultada el 15 de diciembre de 2017.

${ }^{13}$ Ibid., nn. 45 y 65 . 
a las finanzas y a la economía, pone de manifiesto sus desequilibrios y, sobre todo, la grave carencia de su orientación antropológica que reduce al ser humano a una sola de sus necesidades: el consumo. ${ }^{14}$

A los empresarios y, en general, a las grandes empresas, el papa Francisco dirigió las siguientes palabras: "La vocación de un empresario es una noble tarea, siempre que se deje interpelar por un sentido más amplio de la vida; esto le permite servir verdaderamente al bien común, con su esfuerzo por multiplicar y volver más accesibles para todos los bienes de este mundo". ${ }^{15} \mathrm{Y}$ a los políticos les dijo: "La política, tan denigrada, es una altísima vocación, es una de las formas más preciosas de la caridad, porque busca el bien común". ${ }^{16}$

Es imperioso que los gobernantes y los poderes financieros levanten la mirada y amplíen sus perspectivas, que procuren que haya trabajo digno, educación y cuidado de la salud para todos los ciudadanos [...] ¿Por qué no dirigirse a Dios y pedirle que inspire sus planes? Estoy firmemente convencido de que la apertura a lo trascendente puede generar una nueva mentalidad política y económica que ayude a romper el muro de separación entre la economía y el bien común de la sociedad. ${ }^{17}$

De acuerdo con el mensaje del Evangelio, el papa Francisco ve que la reforma de las finanzas mundiales pasa por una verdadera metanoia de los políticos, los empresarios y los otros agentes económicos.

Al mismo tiempo, el Santo Padre desea una reforma desde la base, que libere a los pobres de la cárcel de un asistencialismo dirigido a la dominación política de las masas y que los responsabilice y haga florecer las fuerzas de los individuos, de las familias y de los grupos intermedios.

Es bien sabido que en la Edad Media y en el Renacimiento temprano, el pueblo cristiano, alentado y dirigido por los predicadores franciscanos,

${ }^{14}$ Papa Francisco, Evangelii Gaudium, 24 de noviembre de 2013, n. 55, en $<$ http://w2.vatican. $\mathrm{va} /$ content/francesco/es/apost_exhortations/documents/papa-francesco_esortazioneap_20131124_evangelii-gaudium.html>, consultada el 15 de diciembre de 2017.

${ }^{15}$ Ibid., n. 203.

${ }^{16}$ Ibid., n. 205.

${ }^{17}$ Loc. cit. 
respondió a la financiación relacionada con el poder con la financiación relacionada con la gente, estructurada por casas de empeño.

A finales del siglo XIX se fundaron las cooperativas que, como recuerda el papa Francisco, fueron también la respuesta a la primera "globalización capitalista", la cual, junto con progresos evidentes, trajo también innumerables sufrimientos para los pueblos europeos y generó controversias imperialistas que condujeron a la Primera Guerra Mundial.

Por lo tanto, el papa Francisco apela a los comienzos de la doctrina social de la Iglesia, recuerda en particular la figura de León XIII y promueve todas las formas de acciones cooperativas y otros tipos de nuevas empresas. En ocasión de un encuentro con los representantes de la Confederación Cooperativa Italiana que se llevó a cabo el 28 de febrero de 2015, el papa Francisco dijo:

No es fácil hablar de dinero. Decía Basilio de Cesarea, Padre de la Iglesia del siglo IV, citado luego por san Francisco de Asís, que "el dinero es el estiércol del diablo". Lo repite ahora también el papa: "el dinero es el estiércol del diablo". Cuando el dinero se convierte en un ídolo, dirige las opciones del hombre. Y entonces arruina al hombre y lo condena. Lo hace un esclavo. El dinero al servicio de la vida puede ser gestionado en la forma justa por la cooperativa, si es una cooperativa auténtica, verdadera, donde no manda el capital sobre los hombres, sino los hombres sobre el capital [...] El quinto aliento tal vez os sorprenderá. Para hacer todas estas cosas se necesita dinero. Las cooperativas, en general, no fueron fundadas por grandes capitalistas, es más, se dice a menudo que las mismas están estructuralmente subcapitalizadas. En cambio, el papa os dice: debéis invertir, y debéis invertir bien. En Italia ciertamente, pero no solo, es difícil obtener dinero público para cubrir la escasez de recursos. La solución que os propongo es esta: unid con determinación los medios buenos para realizar obras buenas. Colaborad más entre cooperativas bancarias y empresas, organizad los recursos para hacer vivir con dignidad y serenidad a las familias; pagad salarios justos a los trabajadores, invirtiendo sobre todo en las iniciativas que sean verdaderamente necesarias. [...] La economía cooperativa, si es auténtica [...] debe perseguir finalidades transparentes y claras. Debe promover la economía de la honradez. Una economía saneada en el mar insidioso de la economía global. 
ROBERTO ZOCCO

Una verdadera economía promovida por personas que tienen en el corazón y en la mente solo el bien común. ${ }^{18}$

\section{Conclusiones}

En conclusión, el cardenal Parolin dijo que hay un vínculo claro entre las grandes finanzas, el ejercicio del poder y la competencia entre los distintos centros de poder. Es difícil establecer la precedencia entre las reivindicaciones imperiales y las finanzas, y probablemente se alimentan unas de otras. Por lo tanto, los grandes capitales tienden a financiar los poderes establecidos y los negocios más rentables, "generalmente aquellos de tecnología avanzada", y el crédito no es accesible al pueblo.

Ante este panorama, la Iglesia católica "y con ella la Santa Sede" no se rinde al estado de cosas y persevera en recordar la dignidad del ser humano. En los asuntos que hemos expuestos aquí, significa:

1. Condenar la guerra y cualquier soberbia o egoísmo nacionalista, incluso en sus manifestaciones financieras.

66 2. Promover la responsabilidad ética de los principales agentes políticos o económicos.

3. Fomentar la participación libre y efectiva de los pobres en la construcción de su propia dignidad económica.

${ }^{18}$ Francisco, Discurso a los representantes de la Confederación Italiana de Cooperativas, 28 de febrero de 2015, en $<$ https://w2.vatican.va/content/francesco/es/speeches/2015/february/ documents/papa-francesco_20150228_confcooperative.html >, consultada el 15 de diciembre de 2017. 